\title{
Corrigendum: Long-Term Risk Factors for Intracranial In-Stent Restenosis From a Multicenter Trial of Stenting for Symptomatic Intracranial Artery Stenosis Registry in China
}

\author{
Xu Guo ${ }^{\dagger}$, Ning Ma, Feng Gao, Da-Peng Mo, Gang Luo and Zhong-Rong Miao* \\ Department of Interventional Neuroradiology, Beijing Tiantan Hospital, Capital Medical University, Beijing, China
}

Keywords: cerebrovascular disease, stroke, endovascular treatment, interventional neurology, intracranial instent restenosis

\section{OPEN ACCESS}

Approved by:

Frontiers Editorial Office,

Frontiers Media SA, Switzerland

*Correspondence:

Zhong-Rong Miao

zhongrongm@163.com

TORCID:

Xu Guo

orcid.org/0000-0002-8617-3476

Specialty section:

This article was submitted to Endovascular and Interventional

Neurology,

a section of the journal

Frontiers in Neurology

Received: 27 February 2021 Accepted: 01 March 2021

Published: 30 March 2021

Citation:

Guo X, Ma N, Gao F, Mo D-P, Luo G and Miao Z-R (2021) Corrigendum: Long-Term Risk Factors for Intracranial In-Stent Restenosis From

a Multicenter Trial of Stenting for

Symptomatic Intracranial Artery

Stenosis Registry in China.

Front. Neurol. 12:673264.

doi: 10.3389/fneur.2021.673264

\section{A Corrigendum on}

Long-Term Risk Factors for Intracranial In-Stent Restenosis From a Multicenter Trial of Stenting for Symptomatic Intracranial Artery Stenosis Registry in China by Guo, X., Ma, N., Gao, F., Mo, D.-P., Luo, G., and Miao, Z.-R. (2021). Front. Neurol. 11:601199. doi: 10.3389/fneur.2020.601199

In the original article, there were errors. Three numbers were incorrectly added due to mistaken data import from SPSS into the submitted manuscript. A correction has been made to Discussion, The Type and Length of the Stent, Paragraph 1. The corrected paragraph is shown below.

In our controlled study, the rate of ISR $\geq 50 \%$ was significantly higher in the balloon-mounted stent group than in the self-expandable stent group (33.3 vs. $12.5 \%$ ). The rate of restenosis was slightly higher than that in our earlier study $(20.3 \%)$ with coronary artery stents and the VISSIT study $(26.5 \%)(4,16)$, but was similar to Jin's study, which showed that the restenosis rate with the Apollo stent was $27.5 \%$ (24/87) vs. the Wingspan, which was $24.6 \%(17 / 69)$. In a recent study, Baik et al. reported insertion of a balloon-expandable stent (BES) with symptomatic middle cerebral artery stenosis, and the overall incidence of restenosis or reocclusion was $14.7 \%(5 / 34)$ with long-term follow-up (17). We concluded that 19 patients presented restenosis by performing balloon-mounted stents, including seven cases with basilar artery stenosis and four cases with intracranial vertebral artery stenosis. Therefore, in-stent restenosis of endovascular treatment for stenosis with this type of stent could be associated with the location of lesions, particularly in the posterior circulation.

The authors apologize for these errors and state that they do not change the scientific conclusions of the article in any way. The original article has been updated.

Copyright $\odot 2021 \mathrm{Guo}, \mathrm{Ma}, \mathrm{Gao}, \mathrm{Mo}$, Luo and Miao. This is an open-access article distributed under the terms of the Creative Commons Attribution License (CC BY). The use, distribution or reproduction in other forums is permitted, provided the original author(s) and the copyright owner(s) are credited and that the original publication in this journal is cited, in accordance with accepted academic practice. No use, distribution or reproduction is permitted which does not comply with these terms. 